\title{
COnE).(OES
}

CIÊNCIA E TECNOLOGIA

\section{ASTRONOMIA NO ENSINO FUNDAMENTAL: O OLHAR PARA “SI" COMO INSTRUMENTO DE COMPREENSÃO DO UNIVERSO}

\author{
Ana Clara Souza Araújo ${ }^{1}$, Francélio Ângelo de Oliveira ${ }^{1}$ \\ ${ }^{1}$ Instituto Federal de Educação, Ciência e Tecnologia do Ceará - IFCE \\ <anaclara102329@gmail.com><oliveira.angelo@ifce.edu.br> \\ DOI: <https://doi.org/10.21439/conexoes.v13i4.1861>
}

\begin{abstract}
Resumo. O presente artigo discorre sobre o ensino de astronomia como ferramenta de ensino aprendizagem e como essa ciência é capaz de levar o discente a reflexão sobre seu papel no universo e na sociedade no qual está inserido. O artigo leva ao questionamento sobre a forma que o ensino da Astronomia pode contribuir para a aprendizagem dos alunos do Ensino Fundamental de modo a ampliar o autoconhecimento e a visão sobre seus papéis na sociedade e no universo. Trata-se de um relato de experiência de um projeto de extensão realizado em escolas públicas do interior do Estado do Ceará que leva o leitor a refletir sobre a importância da astronomia não apenas como ciência, mas também como filosofia de vida. A metodologia abordada foi de aula expositiva dialogada para uma maior interação entre professor e aluno, e o método avaliativo para fins de resultados foi aplicação de um questionário aos alunos participantes. A reflexão aqui abordada é uma faixa de mão dupla, uma vez que menciona a relação homem com homem e homem com universo. Os resultados da aplicação do projeto apontam que além de propagar o conhecimento científico, o ensino de astronomia leva o aluno a se descobrir como agente modificador da sua realidade, descobridor dos fascínios do universo.
\end{abstract}

Palavras-chaves: Astronomia, ferramenta de aprendizagem, relações humanas.

\begin{abstract}
This article discusses the teaching of astronomy as a teaching and learning tool and how this science is able to lead the student to reflect on its role in the universe and in the society in which it is inserted. The article raises questions about how astronomy teaching can contribute to elementary school students' learning in order to broaden their self-knowledge and insight into their roles in society and the universe. This is an experience report of an extension project carried out in public schools in the interior of the state of Ceará that leads the reader to reflect on the importance of astronomy not only as a science, but also as a philosophy of life. The methodology approached was a dialogued lecture for greater interaction between teacher and student, and the evaluation method for results was the application of a questionnaire to the participating students. The reflection addressed here is a two-way track, as it mentions the relationship man with man and man with universe. The results of the project application indicate that besides propagating scientific knowledge, the teaching of astronomy leads the student to discover himself as a modifying agent of his reality, discoverer of the fascinations of the universe.
\end{abstract}

Keywords: Astronomy, learning tool, human relations.

\section{INTRODUÇÃO}

A astronomia surgiu da necessidade do homem primitivo em explicar e prever os fenômenos que aconteciam no interior do planeta terra. Desde os primórdios, essa ciência tem sido uma ferramenta poderosa para mudar a maneira de se ver o mundo. Foi através da astronomia que os primeiros homens começaram a se localizar no planeta através da posição de estrelas, compreender os períodos essenciais para um bom plantio tendo como base as épocas de secas e cheias, e consequentemente começaram a entender os acontecimentos que regem o funcionamento da terra e como esta se relaciona com o cosmos (BRETONES, 2013). 
Analisando os pontos positivos que a astronomia trouxe para a humanidade e observando o déficit de aprendizagem de alunos de escolas públicas de nível fundamental, principalmente em ter uma visão espacial (SOLER; LEITE, 2012), o que é pré-requisito para diversos outros conteúdos, como forma de melhorar o desempenho e a aprendizagem e inserir cada vez mais esses discentes no ambiente escolar pensou-se então em levar o ensino da astronomia para essas escolas.

$\mathrm{O}$ ensino da Astronomia pode desmistificar algumas ideias de senso comum sobre fenômenos celestes, como por exemplo: os eclipses e o que eles causam; o aparecimento misterioso de objetos brilhantes e desconhecidos no céu; o eventual impacto destruidor de um cometa na Terra; o apagamento do Sol e as "estrelas cadentes". Do mesmo modo apontar o dedo para o céu, a influência dos astros na vida e na personalidade dos seres humanos e o conceito de campo gravitacional (NARDI; ROULET; TOMMASINI, 1994; NARDI 1991; LANGHI, 2004, LANGHI; NARDI, 2005, NEVES 2005) são práticas e ideias geradas pelo senso comum e são reforçadas por erros conceituais encontrados em livros didáticos (LANGHI; NARDI, 2007). Por isso, levar o aluno a compreender o que há de verdadeiro, liberta o discente de temores e ignorância, como já mencionado.

Diversos modelos e conceitos errôneos são encontrados nos materiais de apoio pedagógico e isso acaba dificultando o aprendizado do aluno, cabendo a ele compreender e colher o conhecimento que realmente está por trás de todo obstáculo que porventura possa ser encontrado (PINTO; VIANNA, 2015). O estudo da astronomia e da cosmologia no ensino básico pode ser usado como um incitador da curiosidade e introdutor do método científico, um conteúdo que pode ser trabalhado de forma interdisciplinar, de maneira que ele pode atrair a atenção de estudantes com diferentes interesses, ou seja, aqueles que tem uma maior facilidade em aprender matemática, biologia, história, geografia, artes ou qualquer outra disciplina (BRASIL, 1998, p. 48).

Os primeiros registros da astronomia, surgiram no antigo Egito. Lá, os egípcios a utilizavam para prevê as cheias do rio Nilo e foram os primeiros a desenvolver calendários anuais. Para os babilônios, a astronomia foi de grande importância, pois foi através dela que passou-se a observar os movimentos do Sol e da Lua, e também conseguiam prever o surgimento da Lua nova. Foi também utilizando a astronomia que os babilônios conseguiram desmistificar os eclipses solares e lunares que nada tinham a ver com presságios (JARAMILLO; TAMAYO-OSORIO, 2012). Desse modo, a astronomia foi uma forma encontrada pelo homem de suprir suas necessidades sociais, econômicas e religiosas, pois entender como funciona o universo, é de vital importância, uma vez que compreender o meio no qual se vive é garantir a própria sobrevivência.

Perceber a astronomia não apenas como uma forma sistematizada do homem se relacionar com o espaço no qual se vive, mas também como uma maneira de correlacionar o homem com o seu interior, levando-o a crescer numa função exponencial de dentro para fora e fazendo com que tenha uma maior harmonia entre homem e natureza, é de grande importância uma vez que o ensino da astronomia pode ser aplicado tanto para orientar a relação homem e natureza, quanto a relação homem consigo mesmo.

Segundo pesquisas realizadas pelo jornal Diário do Nordeste (2015) as escolas do interior do Ceará, não possuem estrutura material, física e profissional adequada. Logo apresentam um maior desafio na aprendizagem por não possuírem uma estrutura que abrigue os alunos da forma como deve ser. Nessa perspectiva, a astronomia no ensino fundamental, tem sido uma forma de instigar e mudar o conceito de universo para os alunos (IVIE, 2013), incentivando-os a buscar sempre mais conhecimento e ajudando nas suas habilidades cognitivas.

Analisando o ambiente escolar de ensino fundamental, as necessidades e dificuldades que os alunos têm para absorver alguns dos conteúdos mais essenciais da matriz curricular e com o intuito de inserir cada vez mais os discentes no âmbito escolar, a seguinte pergunta foi feita: De que forma o ensino da Astronomia pode contribuir para a aprendizagem dos alunos do Ensino Fundamental de modo a ampliar o autoconhecimento e a visão sobre seus papéis na sociedade e no universo? Com as pesquisas feitas na área de astronomia e percebendo as contribuições valiosas dessa ciência, surgiu como ideia para responder a tal indagação, o uso da Astronomia como ferramenta de ensino e aprendizagem com um olhar para "si" com o propósito de compreender o universo.

A possibilidade do inédito, do desconhecido, influencia e incentiva alunos que antes não tinham nenhuma perspectiva profissional ou até mesmo que desconheciam seus papéis como ser humano, a se imaginar em um cenário onde o indivíduo é o protagonista e ser ativo da sua própria história. O desafio de compreender o que está além dos olhos, estimula e atrai as potencialidades que há no âmago de cada um.

A astronomia como ciência que explica os fenômenos que ocorrem no universo, mudou a compreensão do 
homem, desde o início dos tempos, começando por coisas simples, como épocas de plantio até eventos mais complexos como os eclipses. Ao longo do tempo, essa ciência evoluiu com a mesma proporcionalidade que a raça humana, trazendo novas descobertas. Pesquisar sobre a Astronomia, entende-la nas suas mais variadas perspectivas, começou a fazer com que o ser humano começasse a se questionar a respeito do seu papel no imenso universo. Com os questionamentos, o ser humano se descobriu, como um ser ativo, modificador da natureza (LANGHI, 2004). Levando essa ciência como objeto de estudo e ferramenta facilitadora do ensino, para alunos do ensino fundamental, observou-se um alargamento de conhecimentos, nunca antes visto e uma interação mais sólida, entre alunos, professor e escola.

Rodrigues (2014), em seu livro Sociologia da Educação, defende a premissa de que levar os indivíduos a se questionarem a respeito do que são e os seus papéis na sociedade, quebra com toda a ideologia organizada por um sistema que se perpetua ao longo dos séculos. Tornar um indivíduo idiossincrático, significa parar de olhar o indivíduo como mais um, e começar a olhálo através de suas particularidades. A astronomia, tem a capacidade de atender e quebrar com essa visão de mundo imposta desde muito tempo. Deste modo, é de extrema importância saber como a astronomia colabora na vida dos alunos, uma vez que ela consegue ultrapassar as barreiras profissionais e estudantis dos discentes, levando-os a modificarem sua visão de universo e até mesmo a visão que tem de si.

De acordo com uma entrevista realizada pela TV Escola (ESPINELLI; LIMA, 2018) com as astrônomas Patrícia Espinelli, do Museu de Astronomia de São Paulo e Flavia Lima do planetário do Rio de Janeiro, o ensino de astronomia no ensino fundamental tem grande relevância cognitiva para os alunos, uma vez que através de maquetes, representações 3D e vídeos, os alunos começam a aprimorar aspectos de uma visão tridimensional, tendo os mesmos uma maior facilidade de compreender e absorver conteúdos da base curricular comum, como geometria espacial.

A inserção do ensino de astronomia no ensino fundamental, é de extrema importância acarretando benefícios para os alunos, levando-os a ter uma visão geográfica espacial, pois é por meio desse aprimoramento que o discente passa a compreender o seu verdadeiro lugar no universo, uma vez que é muito fácil deturpar o verdadeiro significado do que o homem é para o Cosmos. Para os Parâmetros Curriculares Nacionais (DIAS, 2008) e pelos Parâmetros Nacionais Curricula- res para o Ensino Médio (BRASIL, 2002) a Astronomia um campo de conhecimento indispensável à compreensão de lugar. Isso significa que é através da astronomia, que pode-se compreender a história da humanidade dentro do Cosmos.

O ensino de astronomia, além de ter grande importância na evolução da sociedade como um organismo único, também tem sido de grande valia na inclusão de estudantes dentro do meio social. Pois através de aulas expositivas, oficinas e até mesmo observações noturnas, a astronomia vem desempenhando um papel vital na formação de jovens e adolescentes, formação essa não só profissional, mas também como forma do indivíduo se descobrir como ser ativo e não ser passivo, descobridor dentro da própria sociedade.

De acordo com Langhi e Nardi (2009), o ensino de astronomia no Brasil está amplamente difundido em sete grandes áreas: educação básica, graduação e pós graduação, extensão, pesquisa, popularização midiática, estabelecimentos e materiais didáticos. É através dessa subdivisão, que o ensino da astronomia se propaga gradativamente. Esses grandes campos estão intimamente ligados de tal forma que um necessita do outro para fazer sentido. É no processo de educação básica que começa a construção do alicerce de conhecimentos, para posteriores avanços, de tal forma que fica claro a importância do ensino de astronomia na educação básica, não apenas pelo conhecimento informacional, mas como agente modificador interno.

A busca pela compensação, pela descoberta, existe em cada um, e a astronomia consegue ajudar a compreender não apenas o que existe além do planeta terra, mas é uma ciência que busca a compreensão que está escondida no recôndito do indivíduo. Dessa forma, levar os alunos a questionarem acerca do que são e seus papéis dentro do universo, usando a astronomia como essa forma de questionamento leva os mesmos a compreenderem que não se torna necessário viajar galáxias ou mesmo sair do planeta, basta apenas olhar para dentro de si. Compreender a si é o primeiro passo para compreender o Cosmos.

Aprender astronomia, segundo Langhi (2004), tem levado o habitante pensante do planeta terra a reestruturações mentais que superam o intelectualismo e o conhecimento por ele mesmo, pois a compreensão das dimensões do universo em que vivemos proporciona o desenvolvimento de aspectos exclusivos da mente humana, tais como fascínio, admiração, curiosidade, contemplação e motivação. Desse modo percebe-se que a astronomia, não é apenas o conhecimento cientifico a ser repassado, mas também um elemento motivador, 
uma vez que é um chamariz para o descobrimento do inédito.

Objetivando compreender de que forma o ensino da astronomia como ferramenta de ensino e aprendizagem modifica as visões dos discentes a respeito dos seus papéis na sociedade e no universo, foi realizado um projeto de extensão, com duração de cinco meses em fase experimental por representantes do Instituto Federal de Educação, Ciência e tecnologia do Ceará-IFCE que propunham levar os conhecimentos de astronomia para a posteriori esses conhecimentos seriam aplicados posteriormente na Olímpiada Brasileira de Astronomia (OBA).

Além dos aspectos motivacional e interdisciplinar, a Astronomia assume um certo grau de popularidade, favorecendo a cultura científica, uma vez que o seu laboratório é natural e gratuito, estando o céu à disposição de todos, facilitando a execução de atividades ao ar livre e que não exigem materiais de alto custo (MOORE; ADAIR, 1990). Tais atividades, contudo, conduzem a uma das características diferenciadoras e didaticamente pouco explorada da Astronomia: a construção mental da tridimensionalidade (LEITE; HOSOUME, 2009).

A abordagem do ensino de astronomia, é discutida por Gama e Henrique (2010) e Langhi (2004), como um conjunto de temas motivadores para discussões histórico filosóficos e para propostas de problematizações, conduzindo o trabalho pedagógico para a consideração de conceitos de outras disciplinas, deixando de ser simplesmente um conjunto de conteúdos a serem ensinados, do ponto de vista da abordagem conteudista, o que justificaria claramente a inserção da astronomia em sala de aula.

O projeto de integração que deu origem ao presente artigo foi construído em cima da necessidade que os alunos do ensino fundamental do interior do Ceará tem em compreender conteúdos que envolvem noção espacial e abstração. Reconhecendo os grandes benefícios que a astronomia trouxe para a humanidade, pensou-se em um projeto de astronomia básica para esses alunos, integrando assim o meio acadêmico e a comunidade externa. A seguir, discutiremos um pouco mais sobre a astronomia de acordo com os parâmetros curriculares do ensino fundamental e a representação da astronomia dentro desse nível de ensino.

\section{FUNDAMENTAÇÃO}

\subsection{Astronomia: discutindo o conceito}

A astronomia, é uma das ciências da natureza que busca compreender todos os fenômenos que ocorrem no espaço sideral, relacionados aos astros celestes (MENDONÇA, 2018). Desde o início dos tempos a astronomia foi utilizada como ferramenta de orientação dos povos, e assim como as civilizações ao longo da história, a mesma evoluiu. Mas só foi em 276 a.C, com Erastóstenes de Cirênia que a Astronomia começou a ganhar aspectos de ciência. Foi Erastóstenes o primeiro a calcular a circunferência da terra, precisamente (RIDPATH, 2001). Em 190 a.C, surgiu hiparco da Grécia, no qual contribuiu de forma significativa para o avanço da astronomia, uma vez que foi o mesmo que catalogou as primeiras estrelas e também tomou conclusões importantes sobre o posicionamento do sol e da lua (JARAMILLO; TAMAYO-OSORIO, 2012).

Dessa forma a Astronomia, foi uma maneira que o homem encontrou para suprir suas necessidades política, econômicas e até religiosas. Sendo assim, desde os primórdios buscou-se entender, através desse conjunto de conhecimentos que estavam sendo construídos os fenômenos que ocorriam. E esses conhecimentos, através da sistematização do saber foi sendo repassado de geração.

Nos seus primórdios, a astronomia esteve vinculada a religião, mas com o passar do tempo essa ciência afastou-se do senso comum, e começou a ser mais objetiva. Antes da invenção dos vários tipos de telescópios, a astronomia era realizada essencialmente pela observação a olho nu, com a utilização de equipamentos para a medição das posições dos astros na abóbada celeste e dos horários de observação. Além de equipamentos especializados, as sociedades desenvolvidas construíram observatórios astronômicos na forma de pirâmides, por exemplo no Egito pré-histórico (3.000 a.C.), no Império Maia na América Central (1.000 a.C.), no Império Inca, no Peru (século XIV), e no Império Asteca no México (século XV), etc. (SOARES, 2016).

A Astronomia é uma área do conhecimento bastante ampla e com várias subdivisões. Entre elas, podemos destacar:

1. A Astrobiologia, que relaciona-se com a evolução de sistemas biológicos no universo.

2. A Astrofísica, que estuda as propriedades físicas dos corpos celestes, como sua densidade, temperatura, luminosidade, entre outros.

3. e a Astronomia planetária, no qual estuda os sistemas planetários, com ênfase no sistema solar, que reúne física nuclear, geologia, meteorologia etc. (MENDONÇA, 2018) 
Interdisciplinar, a Astronomia agrega no currículo conhecimentos de matemática, física e química, além de ciência da computação e até mesmo geologia. Por isso, astrônomos usam essas disciplinas para estudar as regências das leis do universo a descobrirem como funcionam estrelas, planetas, satélites, galáxias, entre outros elementos. Portanto, as pesquisas científicas não se limitam ao espaço celeste. Astrônomos e outros cientistas especializados na área aplicam muitos de seus conhecimentos para realizar inovações da medicina, biologia e computação (FOC, 2014).

Com a evolução da astronomia, outras áreas, como a indústria, a tecnologia aeroespacial e a energia, também tiveram avanços significativos (STEFANELLI, 2014). Assim o desenvolvimento científico e tecnológico está intimamente ligado ao índice de desenvolvimento humano de um país ou região. É fácil de perceber que se a pobreza e a fome são uma prioridade, qualquer atividade secundária que não tente resolver diretamente essas questões não é fácil de justificar e apoiar. No entanto, diversos estudos relatam que investimentos em ciência e tecnologia em situações de crise têm vindo a ajudar países a enfrentar e ultrapassar as mesmas, mostrando que o investimento em ciências básicas têm, não só um grande retorno cultural e humano, mas também um retorno econômico.

Hoje em dia, a astronomia e áreas afins estão na vanguarda da ciência e tecnologia, respondem a questões elementares sobre a nossa existência, inspiram artistas, escritores e sonhadores, geram riqueza e impulsionam a inovação e a economia (RUSSO, 2009). Por isso sua relevância e inserção nos PCN's.

\subsection{Astronomia no Ensino Fundamental}

Até dezembro de 1996 o ensino fundamental esteve estruturado nos termos previstos pela Lei Federal $n^{\circ}$ 5.692, de 11 de agosto de 1971. Essa lei, ao definir as diretrizes e bases da educação nacional, estabeleceu como objetivo geral, tanto para o ensino fundamental quanto para o ensino médio, proporcionar aos educandos a formação necessária ao desenvolvimento de suas potencialidades como elemento de auto realização, preparação para o trabalho e para o exercício consciente da cidadania (PCN introdutório).

Os PCNs como forma de garantir uma base educativa para todos, explicita a importância de uma educação completa

\footnotetext{
"Em linha de síntese, pode-se afirmar que o currículo, tanto para o ensino fundamental quanto para o ensino médio, deve obrigatoriamente propiciar oportunidades
}

para o (...) mundo físico e natural e da realidade social e política, enfatizando-se o conhecimento do Brasil." (BRASIL 1997).

A astronomia, como um todo não é garantida dentro dos Parâmetros Curriculares Nacionais, mas alguns conteúdos de sua abrangência foram distribuídos dentro de outras disciplinas como geografia e ciências naturais. Na geografia, por exemplo, o estudo de fusos horários e localização espacial, são conteúdos astronômicos. Já nas ciências naturais o estudo de planetas também é conteúdo astronômico. Todavia, esses conteúdos astronômicos presentes em outras disciplinas, são altamente cientificista, isso significa, que atendem ao método científico, obedecendo à risca as regras, não levando os alunos a pensarem, mas sim apenas reproduzirem o que foi passado.

$\mathrm{O}$ objetivo fundamental do ensino de Ciências (SANTOS; COSTA, 2017), passou a ser o de dar condições para o aluno identificar problemas a partir de observações sobre um fato, levantar hipóteses, testá-las, refutá-las e abandoná-las quando fosse o caso, trabalhando de forma a tirar conclusões sozinho. O aluno deveria ser capaz de "redescobrir" o já conhecido pela ciência, apropriando-se da sua forma de trabalho, compreendida então como "o método científico", que é uma sequência rígida de etapas preestabelecidas. É com essa perspectiva que se buscava, naquela ocasião, a democratização do conhecimento científico, reconhecendose a importância da vivência científica não apenas para eventuais futuros cientistas, mas também para o cidadão com um todo.

Já a Geografia, tem sido a mediadora (FERNANDES, 2008), das abordagens singulares que os homens em sociedade estabelecem com a natureza. Essas dimensões são socialmente elaboradas, fruto das experiências individuais marcadas pela cultura na qual se encontram inseridas, resultantes em diferentes percepções do espaço geográfico e sua construção. Uma Geografia que não seja apenas centrada na descrição empírica das paisagens, tampouco pautada exclusivamente na interpretação política e econômica do mundo; que trabalhe tanto as relações socioculturais da paisagem como os elementos físicos e biológicos que dela fazem parte, investigando as múltiplas interações entre eles estabelecidas na constituição de um espaço: o espaço geográfico.

Segundo os PCN's - Parâmetros Curriculares Nacionais de Ciências - o eixo Terra e Universo propõe uma abordagem histórica muito carregada dos antigos filósofos e cientistas para tentar compreender o céu, a origem de tudo, como a vida surgiu, o que existe além nas fronteiras do espaço e diversos outros questiona- 
mentos (Brasil, 1998). Compreende-se que estes pensadores tiveram a curiosidade de tentar compreender os fenômenos naturais que ocorrem no Planeta Terra e no Universo como um todo, embora não se tinha noção de sua grandiosidade, naquela época (LEONêS, 2011).

O objetivo de se trabalhar o conteúdo Terra e Universo é introduzir os alunos ao conhecimento científico através dos estudos em astronomia como forma de ampliar o conhecimento espaço - temporal e dar um enfoque no sistema Sol-Terra-Lua. Nesse sentido, busca-se que os estudantes tenham a percepção dos fenômenos astronômicos e os relacione ao cotidiano (PINTO; VIANNA, 2015). Assim, os alunos entenderão que os assuntos envolvendo astronomia estão em toda parte, no nascer e no pôr do sol, nas estações do ano, nas festas em geral (natal e páscoa, por exemplo), no calendário, no clima, no movimento real e aparente dos corpos celestes no céu noturno, etc.

A ideia de que a astronomia tem papel integrador não só do conhecimento, é reforçada por Langhi e Nardi (2009), mas também na aproximação do público de todas as idades, seja qual for o nível de ensino, podendo se utilizar de instituições de ensino, clubes de astronomia e órgãos não governamentais que por iniciativa própria, tentam promover o ensino e o conhecimento da astronomia em suas respectivas regiões.

Assim, busca-se envolver o aluno nesta temática para que ele possa manifestar argumentos e conhecimento para o seu próprio benefício na carreira acadêmica ou mesmo no mercado de trabalho. Caniato, em seu pequeno conto “O Joãozinho da Maré” (1989), mostra que qualquer pessoa pode observar e interpretar o ambiente a sua volta, podendo, assim, tirar conclusões empiricamente.

\section{Metodologia}

\subsection{Caracterização do lócus da pesquisa}

O presente projeto foi aplicado na escola municipal de ensino fundamental Hermínia Franklina da Silveira, situada no distrito de Juritianha, na cidade de Acaraú, interior do estado do Ceará. O núcleo gestor é composto pelo diretor, coordenadoras e secretárias. Os professores são ao total, dez, distribuídos entre as disciplinas de português, matemática, inglês, história, geografia, ciências e educação física, nos períodos matutino e vespertino.

É importante acrescentar que infelizmente ainda há uma certa resistência por parte da maioria das instituições de ensino no que diz respeito a aderir um projeto novo, que ainda está em fase de aplicações e testes. Por isso que encontrar uma escola que possa aderir novas ideias e que incentivem os alunos a buscá-las, é um dos passos primordiais, para o desenvolvimento do projeto.

A escola foi escolhida pelo critério de flexibilização e incentivo por parte dos docentes aos discentes a ampliar seus horizontes e buscar o inédito, o que justamente o ensino de astronomia é capaz de trazer. Por dá o poder de escolha ao aluno e total autonomia, a escola foi perfeita para essa primeira fase experimental do projeto.

É de extrema importância que a instituição de ensino possa dá a liberdade ao discente, isso faz com que o aluno desenvolva um pensamento crítico. E ter essa capacidade é fundamental para transformar o indivíduo em ser modificador do universo, mostrando que é possível sim se desvencilhar do sistema imposto, deixando para trás o indivíduo reprodutor e aderindo ao indivíduo modificador.

\subsection{Os sujeitos participantes da pesquisa}

A escolha dos alunos se deu de acordo com a disposição dos mesmos e pela afinidade dos discentes com o assunto em questão. Os alunos ficaram livres para decidir se participariam ou não. No total, foram quinze alunos a participar do projeto. Esses alunos foram das turmas de oitavo e nono ano, do período da tarde, e a aplicação do projeto se deu pelo horário da manhã a fim de não interferir nos seus horários normais de aula.

Os alunos de oitavo e nono ano foram escolhidos por terem uma maturidade maior com o conteúdo, e por já terem estudado conteúdos que facilitaram a aprendizagem dos conteúdos de astronomia ministrados. Por serem alunos muito jovens ainda, a expectativa e o fascínio pelo conteúdo novo, fizeram dos discentes excelentes espectadores dentro da sala de aula, contribuindo para um maior aproveitamento do tempo e dos conteúdos.

\subsection{Procedimentos}

A metodologia consistiu na aplicação do projeto "Astronomia no Ensino Fundamental" e revisão bibliográfica dos PCNs. De início foram selecionados alunos de turmas de 8 e 9 ano do ensino fundamental para aplicar o método de aula expositiva dialogada, que caracterizase pela exposição de conteúdos com a participação ativa dos estudantes, considerando o conhecimento prévio dos mesmos, sendo o professor o mediador para que os alunos questionem, interpretem e discutam o objeto de estudo (NUNES 2015). 
Os conteúdos ministrados em sala, envolveram a astronomia na antiguidade, o sistema solar e modelos geométricos. A didática apresentada se mostrou transversal, envolvendo interdisciplinaridade, uma vez que além dos conteúdos de astronomia abordados, conteúdos de sociologia e filosofia também fizeram parte da ministração das aulas. Além de oficinas de construção de lunetas e observações noturnas do céu com o apoio do Clube de Astronomia Voyage (CAV).

A astronomia em si, é altamente interdisciplinar pois faz com que tenha possibilidades de diversas interfaces com outras disciplinas, e isso desperta o valor da pesquisa científica nos discentes (LANGHI, 2004). Deste modo, percebesse que a astronomia, é uma ferramenta poderosa e agente modificadora, uma vez que a mesma leva os discentes a se questionarem a respeito dos seus papéis no universo. Na Tabela 1 é mostrado o crnograma de aplicação do projeto.

Na primeira coluna, encontram-se os meses de aplicação efetiva do projeto, os três meses iniciais, foram compostos por planejamentos de como seria a ministração das aulas. Na segunda coluna, está exposto a relação de conteúdos astronômicos abordados, juntamente com as observações noturnas com o apoio do clube de astronomia do Instituto Federal do Ceará e as oficinas de construção de lunetas caseiras. Os alunos, de início foram instigados a participarem por conta própria, uma vez que o projeto destinou-se a todos que quiseram participar de forma voluntária. Em seguida, mapeando a realidade dos discentes pôde-se escolher com base nos PCNs os conteúdos as serem ministrados.

Percebe-se que a compreensão de fenômenos mais distantes no tempo e no espaço começa a ser possível quando desde as séries iniciais os alunos são incentivados a conhecerem mais do universo. Por exemplo, as referências de distância entre os corpos celestes conhecidos, bem como os conceitos de força da gravidade, de forma qualitativa, envolvidos nos movimentos da Terra e dos outros corpos celestes podem ser discutidos. Entender a estrutura da galáxia e do Universo e os modelos que as explicam é algo que depende de uma gradativa formação de visão de mundo, mais do que de um conjunto de observações sistemáticas pelos estudantes.

\section{RESULTADOS E DISCUSSÃO}

Os resultados obtidos, após a aplicação do projeto foram de considerável relevância para a inserção do ensino de astronomia no ensino fundamental. Após a aplicação, foi construído um questionário, com cinco questões, na plataforma do Google Forms, em que foram perguntados aos alunos participantes a respeito da ex- periência que tiveram a partir dos conteúdos ministrados, se houve alguma mudança em suas experiências de vida.

De início, os alunos responderam a seguinte questão:

\section{QUESTÃO 1 - Sua visão de universo teve alguma al- teração após as aulas de astronomia?}

$83,3 \%$ dos alunos responderam que muitas coisas mudaram na sua visão de mundo, depois de assistirem as aulas de astronomia, como mostra a Figura 1 .

Figura 1: Resposta da questão 1

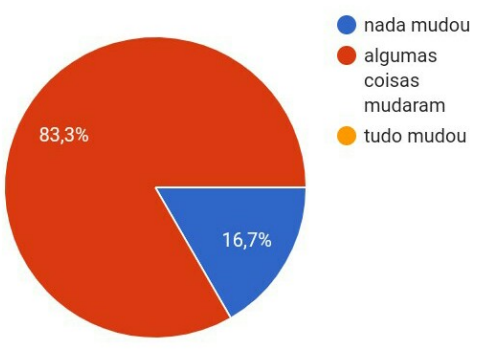

\section{QUESTÃO 2 - Com que frequência conversam sobre astronomia com seus professores e colegas.?}

Apenas $16,7 \%$ disseram que conversas desse tipo eram frequentes, $83,3 \%$ falaram que raramente debatiam sobre o assunto. Os dados encontram-se na Figura 2

Figura 2: Resposta da questão 2

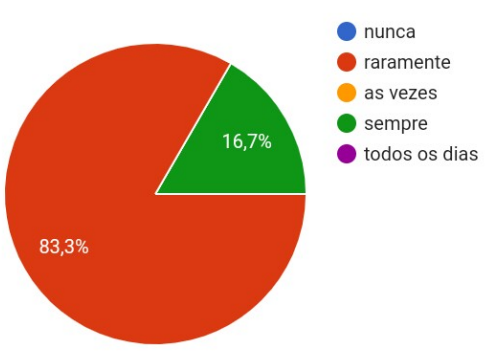


Tabela 1: Cronograma de aplicação do projeto

\begin{tabular}{|l|l|}
\hline \multirow{4}{*}{ FEVEREIRO (2019) - Semana 2} & "Astronomia na antiguidade \\
\cline { 2 - 2 } & O que é astronomia, conceitos básicos \\
\cline { 2 - 2 } & Atividade de fixação \\
\cline { 2 - 2 } & Lista de questões da OBA" \\
\hline \multirow{3}{*}{ FEVEREIRO (2019) - Semana 3} & "O sistema solar em uma representação teatral. \\
\cline { 2 - 2 } & As leis de Kepler- 1 lei das órbitas \\
\cline { 2 - 2 } & Atividade de fixação" \\
\hline \multirow{3}{*}{ FEVEREIRO (2019) - Semana 4} & "2 lei de Kepler- A lei das áreas \\
\cline { 2 - 2 } & Atividade de fixação \\
\cline { 2 - 2 } & 3 lei de Kepler- Lei dos períodos" \\
\hline \multirow{2}{*}{ MARÇO (2019) - Semana 1} & "Os modelos geométricos do sistema solar \\
\cline { 2 - 2 } & Astronomia Medieval, Nicolau Copérnico, Galileu Galilei, Isaac Newton." \\
\hline \multirow{3}{*}{ MARÇO (2019) - Semana 2} & "Gravitação Universal, Lei da gravitação universal para órbitas circulares. \\
\cline { 2 - 2 } & Lista de questões da OBA \\
\cline { 2 - 2 } & 1 Observação" \\
\hline \multirow{2}{*}{ MARÇO (2019) - Semana 3} & "1 oficina de construção de luneta \\
\cline { 2 - 2 } & 2 oficina de construção de lunetas" \\
\hline \multirow{2}{*}{ MARÇO (2019) - Semana 4} & "3 oficina de encerramento da construção de luneta \\
\cline { 2 - 2 } & 2 Observação \\
\cline { 2 - 2 } & Provinha simulado." \\
\hline
\end{tabular}

Logo após a aplicação do questionário, iniciou-se a fase de pesquisas bibliográficas sobre os Parâmetros Curriculares Nacionais, que ao longo desse texto foi exposto e utilizado como fundamentação teórica.

Durante a experiência foi observado um desenvolvimento significativo, no interesse dos discentes com relação a busca pelo conhecimento sobre o universo e tudo que o compõe. Percebeu-se também a capacidade que o ensino de astronomia tem em modificar a realidade, uma vez que os próprios alunos participantes do projeto, iniciaram com um relato de vida e ao findar o projeto tinham novas perspectivas para o futuro.

Após a conclusão do projeto, a aplicação de questionário e pesquisas bibliográficas, percebeu-se a riqueza de conhecimentos que a astronomia pode trazer para os alunos, e o quanto pode modificar a vida dos discentes. Mais importante do que levar o conhecimento cientifico, a astronomia é capaz de levar os alunos ao questionamento que é tão importante para a formação do homem como ser modificador do universo.

A experiência resultou em um grande aprendizado para os discentes, bem como os ajudou a compreender assuntos que antes era de difícil entendimento. O resultado foi excelente e trouxe uma alternativa de grande relevância para aplicações futuras em outras escolas.

Como a escola já tinha uma certa flexibilização para apoio de novos projetos, o interesse dos alunos e seus esforços, facilitou o desenvolvimento do projeto. Em contrapartida, a dificuldade de locomoção dos alunos no contra turno para participação do projeto e a falta de materiais na escola bem como projetor, cartolina e pinceis não colaboraram para um maior avanço no desenvolvimento do projeto. Para aplicações futuras, seria interessante um maior uso de materiais recicláveis, como o uso de bolinhas de plástico para a representação de planetas em maquetes.

As escolas abertas à diversidade são aquelas em que todos os alunos se sentem respeitados e reconhecidos nas suas diferenças, ou melhor, são escolas que não são indiferentes às diferenças. Ao nos referirmos a essas escolas, estamos tratando de ambientes educacionais que se caracterizam por um ensino de qualidade, que não excluem, não categorizam os alunos em grupos arbitrariamente definidos por perfis de aproveitamento escolar e por avaliações padronizadas e que não admitem a dicotomia entre educação regular e especial. As escolas para todos são escolas inclusivas, em que todos os alunos estudam juntos, em salas de aulas do ensino regular. Esses ambientes educativos desafiam as possibilidades de aprendizagem de todos os alunos, e as estratégias de trabalho pedagógico são adequadas às habilidades e às necessidades de todos (MANTOAN, 2015).

De acordo com Lopes (2009), a relação professoraluno tem sido uma das principais preocupações do contexto escolar, daí a importância de estabelecer uma reflexão aprofundada sobre esse assunto. E o ensino de 
astronomia por levar fascínio e aguçar a curiosidade dos alunos, colabora para que essa experiência seja a melhor possível. É necessário que o educador compreenda que esse relacionamento na teoria é muito diferente da realidade, e que deve-se ter o máximo de paciência e compreensão por parte do professor quanto ao aluno.

Desenvolver o projeto de ensino de astronomia no ensino fundamental, significou expor uma ideia, que traria benefícios aos alunos e suas aprendizagens. Levando o projeto e o aplicando na realidade, compreendeu-se a dificuldade que os alunos tem seja de locomoção, de estrutura escolar ou financeira, o que tornou o projeto ainda mais rico, por contribuir na realidade desses discentes, levando-os a pensarem a respeito de suas aspirações de vida e os ajudando a compreender a realidade do universo a sua volta.

Langhi e Nardi (2010), relata que o papel dos saberes docentes (além dos saberes disciplinares), na formação profissional de professores, tem sido amplamente discutido por autores tais como Pacheco (1995), Porlán e Rivero (1998), dentre outros. No caso específico da Astronomia, os resultados das pesquisas mostram que seus conteúdos não estão sendo trabalhados de maneira significativa, quantitativa e qualitativamente, nem mesmo em cursos de formação inicial de professores. Maluf (2000) e Barros (1997), por exemplo, comprovam a existência de falhas ligadas diretamente à formação inicial do professor com relação a tópicos de Astronomia. Por esse motivo, é necessário que o docente ministrador das aulas, seja apto a atender os requisitos necessários para o ensino de astronomia.

Segundo Queiroz (2008), ter uma ferramenta tão importante como o ensino de astronomia, e aplicar desde as séries iniciais aos alunos, dá a oportunidade as novas gerações de melhor evoluir e levar mais desenvolvimento a uma sociedade que não se dá ao trabalho de tentar entender o seu papel no cosmos, nem de se entender como ser humano.

\section{CONSIDERAÇÕES FINAIS}

Após a pesquisa realizada e a aplicação do projeto, objetivando compreender de que forma o ensino da astronomia como ferramenta de ensino aprendizagem modifica as visões dos discentes a respeito dos seus papéis no universo concluiu-se que o ensino aprendizagem de astronomia é capaz de levar os discentes a refletir sobre sua existência e desenvolver um pensamento crítico a respeito dos seus papéis no universo, compreendendo como o cosmos funciona e encontrando maior harmonia entre espaço e indivíduo.
Entendendo que a astronomia é composta por conteúdos que trabalham tanto com o cálculo e o método cientifico, quanto com a abstração o que leva os alunos a pensarem criticamente e ter uma visão mais aberta com relação ao concreto, percebesse o impacto positivo que essa ferramenta é capaz de trazer a vida dos discentes, impacto esse transformador.

É importante constatar que com o processo de ensino aprendizagem do ensino de astronomia não é só o aluno que torna-se um pensador critico, entendedor do que ocorre no universo, mas como a essa troca de informações e conhecimentos entre aluno e professor, o docente também acaba se revelando ser crítico modificador da sua realidade.

A pertinência do ensino de astronomia ao parecer das pesquisas analisadas, revelam que pode acarretar grandes benefícios para os alunos de ensino fundamental principalmente, uma vez que há provas de expressivo valor que confirmam a ideia e aplicações.

A busca pelo inédito aviva a curiosidade e o espirito de aventura em cada um, conseguir usar isso como forma de incentivar cada vez mais os alunos no meio estudantil, traz a possibilidade de novas maneiras de ajudar o discentes em suas práticas escolares bem como seu próprio desenvolvimento cognitivo, e o ensino de astronomia é uma das ferramentas que podem ser utilizadas nesse processo de ensino aprendizagem.

Complementar a essa ideia, é extremamente importante que os docentes sejam mobilizados a atiçar nos alunos essa ideia de transformação, uma vez que é necessário primeiramente essa quebra de distopia desde sempre imposta e que comecem a se aceitar como seres críticos e modificadores.

Desde a ideia concebida, passando pela aplicação do projeto até a construção do presente artigo, compreendeu-se um pouco da importância e dos impactos do ensino de astronomia. Entretanto, compreendendo que o docente é o principal mediador dentro da sala de aula, é necessário fazer mais estudos voltados ao conhecimento que eles tem sobre a astronomia, e principalmente sobre a abordagem em sala de aula.

É indiscutível que a astronomia leva um certo nível de abstração no seu processo de ensino, uma vez que seu campo de atuação vai além dos limites do que os olhos podem conceber, mas com as ferramentas certas e abordagens dinâmicas é possível compreender a beleza dessa ciência e utilizá-la cada vez mais para a evolução humana.

Após a aplicação do projeto, percebeu-se que os discentes, conseguiram de diferentes maneiras compreender um pouco do universo que os cerca e seus papéis 
como seres críticos e transformadores. Observou-se também, que houve uma contribuição positiva por parte da astronomia, no dia a dia dos alunos em suas aulas regulares.

A experiência educacional descrita no presente artigo, buscou antes de tudo, mostrar o quanto o ensino de astronomia pode ajudar alunos de ensino fundamental, por estarem no início de suas carreiras acadêmicas, a compreenderem o que está ao seu derredor. Compreender as leis que regem os corpos celestes e indagar sobre outras tantas questões, é um importante começo para transformá-los em seres capazes de pensar e formular suas próprias ideias e concepções.

De forma abrangente, os resultados obtidos tanto na observação quanto no questionário aplicado foram satisfatórios e atenderam às expectativas iniciais. A partir da experiência relatada, conclui-se que o uso da astronomia como ferramenta educacional e forma de busca e compreensão do universo com um olhar para si promove mudanças na perspectiva do aluno.

\section{REFERÊNCIAS}

BRASIL. Parâmetros Curriculares. apresentação dos temas transversais. Brasília, 1997. Secretaria de Educação Fundamental.

BRASIL. Parâmetros curriculares nacionais: arte. Mec/sef. Brasília, 1998. Http://portal. mec. gov. br/seb/arquivos/pdf/arte. pdf.

BRASIL. Parâmetros Curriculares Nacionais: "ensino médio". 1. ed. Brasília: Ministério da Educação, 1999. 538-545 p.

BRETONES, P. S. "Jogos para o ensino de astronomia.". 1. ed. Campinas: Átomo , 2013.

CANIATO, R. Com ciência na educação: ideário e prática de uma alternativa brasileira para o ensino da ciência. 1. ed. São Paulo: Papirus Editora, 1987.

CARVALHO, R. E. Educação inclusiva com os pingos nos "is". 1. ed. Porto Alegre: Mediação, 2004.

DINIZ-PEREIRA, J. E. A construção do campo da pesquisa sobre formação de professores. Revista da FAEEBA-Educação e Contemporaneidade, v. 22, n. 40, p. 145-154, 2019.

ESPINELLI, P.; LIMA, F. Astronomia no Ensino Fundamental. 1. ed. São Paulo: TV Escola, 2018.
FERNANDES, A. C. a. O Ensino de Geografia no Curso de Pedagogia. Dissertação (Mestrado em Educação) - Universidade do Oeste Paulista, Presidente Prudente - SP, 2008.

GAMA, L. D.; HENRIQUE, A. B. Astronomia na sala de aula: por quê? Revista Latino-Americana de Educação em Astronomia, v. 1, n. 9, p. 7-15, 2010.

IVIE, R. Mulheres na Faculdade de Física e Astronomia. 1. ed. Instituto Americano de Física: Instituto Americano de Física, 2013.

JARAMILLO, D.; TAMAYO-OSORIO, C. Práticas sociais, currículo e conhecimento matemático: tecidos ao interior de uma escola indígena. In: ROSA, G.; WOFF, M. (Ed.). Educação Básica, políticas e prácticas pedagógica. São Paulo: Editorial Mercado de letras, 2012.

LANGHI, R. Um estudo exploratório para a inserção da Astronomia na formação de professores dos anos iniciais do Ensino Fundamental. 2004. 243f. Dissertação (Mestrado em Educação para a Ciência) - Faculdade de Ciências, Universidade Estadual Paulista, Bauru, 2004.

LANGHI, R.; NARDI, R. Dificuldades de professores dos anos iniciais do ensino fundamental em relação ao ensino da astronomia. Revista Latino-Americana de Educação em Astronomia, v. 1, n. 2, p. 75-91, 2005.

LANGHI, R.; NARDI, R. Ensino de astronomia: Erros conceituais mais comuns presente em livros didáticos de ciência. Caderno Brasileiro de Ensino de Física, Universidade Federal de Santa Catarina (UFSC), v. 24, n. 1, p. 87-111, 2007.

LANGHI, R.; NARDI, R. Educação em astronomia no brasil: alguns recortes. In: XVIII Simpósio Nacional de Ensino de Física. Vitória - ES: SNEF, 2009. p. 1 11.

LEONêS, A. D. S. "Reflexões do ensino de astronomia segundo os PCN e as orientações curriculares em Planaltina DF.". 2011.

MANTOAN, M. T. E. Inclusão Escolar: o que é? por quê? como fazer? 2015. Summus Editorial

MENDONÇA, R. V. H. Bases da informação quântica no ensino médio através da plataforma Moodle. Dissertação (Mestrado Profissional em Ensino de Física) - Universidade Federal de Goiás, Goiás, 2018. 
ASTRONOMIA NO ENSINO FUNDAMENTAL: O OLHAR PARA "SI" COMO INSTRUMENTO DE COMPREENSÃO DO UNIVERSO

MOORE, D. W.; ADAIR, V. Effects of a school-based education programme on safety helmet usage by 11-to 13-year-old cyclists. Educational Psychology, Taylor \& Francis, v. 10, n. 1, p. 73-78, 1990.

NARDI, E.; ROULET, E.; TOMMASINI, D. Limits on neutrino mixing with new heavy particles. Physics Letters B, Elsevier, v. 327, n. 3-4, p. 319-326, 1994.

NARDI, L. Caracterização petrográfica e geoquímica dos granitos metaluminosos da associação alcalina: revisão. Pesquisas em Geociências, v. 18, n. 1, p. 44-57, 1991.

NEVES, L. M. W. A nova pedagogia da hegemonia: estratégias do capital para educar o consenso. 2005. Xamã.

OLIVEIRA, E.; FALK, J.; CARVALHO, M.; GONçALVES, E. Parâmetros curriculares nacionais do ensino médio, formação docente e a gestão escolar. In: Anais do XXVI Simpósio Brasileiro de Política e Administração da Educação. Recife: ANPAE, 2013. p. 1-13.

OLIVEIRA, M.; ROCHA, G. Avaliação em larga escala no brasil nos primeiros anos do ensino fundamental. associação nacional de política e administração da educação. Cadernos Anpae, v. 4, n. 11, p. $11-14,2007$.

PINTO, R. A.; VIANNA, M. d. C. V. As avaliações externas e a escola: possibilidades e desafios para a sala de aula. 2015. Emem.

PUZZO, D. Um estudo das concepções alternativas presentes em professores de Ciências de $5^{\mathrm{a}}$ série do ensino fundamental sobre fases da Lua e eclipses. Dissertação (Mestrado em Ensino de Ciências e Educação Matemática) - Universidade Estadual de Londrina, Londrina, 2005.

QUEIROZ, V. A astronomia presente nas séries iniciais do ensino fundamental das escolas municipais de Londrina. Dissertação (Mestrado em Ensino de Ciências e Educação Matemática) Universidade Estadual de Londrina, Londrina, 2008.

RIDPATH, I. Book review: Collins incyclopedia of the universe/harper-collins, 2001. The Observatory, v. 121, n. 1 , p. $387,2001$.

RODRIGUES, A. T. Sociologia da Educação. 1. ed. Rio de Janeiro: DP \& A, 2014.
RUSSO, P. Porque é a astronomia importante? 2019.

Disponível em: <https://www.1minutoastronomia.org/ 13.html.> Acesso em: 13 ago. 2019.

SANTOS, L. R. O.; COSTA, J. J. Educação ambiental e as ciências da natureza: desafios curriculares frente ao exame nacional do ensino médio. In: Encontro Internacional de Formação de Professores e Fórum Permanente de Inovação Educacional. Aracaju - SE: ANPED, 2017. v. 10, n. 1, p. 1 - 15.

SAVIANI, D. Os saberes implicados na formação do educador. In: Formação do educador: dever do Estado, tarefa da Universidade. São Paulo: Unesp, 1996. p. 145-155.

SOARES, M. Alfabetização: a questão dos métodos. 1. ed. São Paulo: Contexto, 2016.

SOLER, D. R.; LEITE, C. Importância e justificativas para o ensino de astronomia: um olhar para as pesquisas da área. In: II Simpósio Nacional de Educação em Astronomia. São Paulo: SNEA, 2012. p. $370-379$.

STEFANELLI, M. L. Badminton, um esporte com um potencial de incrementação da aderência, da e do adolescente, ao programa de educação física no ensino médio: boa prática em promoção da saúde e estratégias inovadoras. Pensar a Prática, Goiânia, v. 17, n. 4, p. 13, 2014.

VIANA, M. C. V. O. Processo de Ensino/Aprendizagem Sob Diferentes Olhares.

1. ed. Ouro Preto: Centro de Educação Aberta e a Distância da Universidade Federal de Ouro Preto, 2013. 